\title{
Clues toward precision medicine in oral squamous cell carcinoma: utility of next-generation sequencing for the prognostic stratification of high-risk patients harboring neck lymph node extracapsular extension
}

\author{
Hung-Ming Wang ${ }^{1}$, Chun-Ta Liao ${ }^{2}$, Tzu-Chen Yen ${ }^{3}$, Shu-Jen Chen ${ }^{4}$, Li-Yu Lee ${ }^{5}$, \\ Chia-Hsun Hsieh ${ }^{1}$, Chien-Yu Lin ${ }^{6}$ and Shu-Hang $\mathbf{N g}^{7}$ \\ ${ }^{1}$ Department of Internal Medicine, Division of Medical Oncology, Chang Gung Memorial Hospital and Chang Gung University, \\ Taoyuan, Taiwan, ROC \\ 2 Department of Otorhinolaryngology, Section of Head and Neck Surgery, Chang Gung Memorial Hospital and Chang Gung \\ University, Taoyuan, Taiwan, ROC \\ ${ }^{3}$ Department of Nuclear Medicine and Molecular Imaging Center, Chang Gung Memorial Hospital and Chang Gung University, \\ Taoyuan, Taiwan, ROC \\ ${ }^{4}$ ACT Genomics, Taipei, Taiwan, ROC \\ ${ }^{5}$ Department of Pathology, Chang Gung Memorial Hospital and Chang Gung University, Taoyuan, Taiwan, RoC \\ ${ }^{6}$ Department of Radiation Oncology, Chang Gung Memorial Hospital and Chang Gung University, Taoyuan, Taiwan, ROC \\ 7 Department of Diagnostic Radiology, Chang Gung Memorial Hospital and Chang Gung University, Taoyuan, Taiwan, RoC \\ Correspondence to: Hung-Ming Wang, email: whm526@gmail.com \\ Keywords: next-generation sequencing, precision medicine, oral squamous cell carcinoma, extracapsular extension, TP53 DNA- \\ binding domain \\ Received: June 11,2016 Accepted: August 26, $2016 \quad$ Published: August 31, 2016
}

\section{ABSTRACT}

Patients with resected oral squamous cell carcinoma (OSCC) harboring extracapsular extension (ECE) of the involved lymph node, show poor and heterogeneous outcomes. We aim to improve their prognostic stratification by combining genetic information from next-generation sequencing (NGS) using traditional clinicopathological prognosticators. The hotspot mutation regions of $\mathbf{4 5}$ cancer-related genes were investigated using NGS with an ultra-deep ( $>1000 x)$ sequencing approach in formalin-fixed paraffin-embedded samples obtained from 201 patients with resected OSCC harboring ECE. Adjuvant chemoradiotherapy (CRT) and the number of nodes with ECE were the most important traditional prognosticators for disease-specific survival (DSS). The 5-year DSS for patients with CRT versus without, was $55 \%$ versus $21 \%(P<0.001)$, and that for $1-3$ versus $\geq 4$ ECEs was $60 \%$ versus $25 \%(P=0.001)$, respectively. Multivariate analysis in patients who received adjuvant CRT for 1-3 ECEs (i.e., those with a favorable expected prognosis) identified the following adverse prognostic factors: 1) margin of $<5 \mathrm{~mm}$ for locoregional failure (66\% versus $30 \%, P=0.007$ ) and DSS $(42 \%$ versus $63 \%, P=0.039) ; 2$ ) HRAS mutation for distant failure ( $55 \%$ versus $25 \%, P=0.007$ ) and DSS ( $36 \%$ versus $63 \%, P=0.024)$; and 3 ) TP53 DNA-binding domain missense mutations for DSS (52\% versus $71 \%, P=0.025$ ) and overall survival ( $39 \%$ versus $61 \%, P=0.007$ ).

We conclude that genetic information from NGS may improve the prognostic stratification offered by traditional prognosticators in resected OSCC patients with ECE. Our findings will contribute to implementation of precision medicine in OSCC patients. 


\section{INTRODUCTION}

Oral malignancies pose a significant health burden and frequently require complex and expensive treatment. In particular, head and neck squamous cell carcinoma (HNSCC) is the fifth-most common malignancies worldwide, with an incidence of approximately 650,000 new cases per year [1]. Moreover, it ranks as the fourthleading cause of cancer-related death in Taiwanese males [2]. Owing to the endemic habit of chewing betel quid in Southern Asia, oral squamous cell carcinoma (OSCC) accounts for nearly $70 \%$ of all new HNSCC cases in Taiwan [2].

Upfront surgery continues to remain the mainstay of treatment for patients with resectable OSCC. The adverse prognostic impact of extracapsular extension (ECE) in OSCC has been consistently demonstrated [3-6]. A metaanalysis of nine studies collectively examining 2573 patients with HNSCC has shown that the risk of death is 2.7-fold higher when ECE is present in neck lymph nodes [7]. Post-operative, cisplatin-based, adjuvant CRT is currently considered the standard of care for patients with pathologically proven positive margins and/or ECE [8-10]. However, the relatively high locoregional failure (LRF) $(22.3 \%)$ and poor disease-free survival (DFS) rates $(20.1 \%)$ in the long-term [11] pose major clinical hurdles. On the other hand, approximately $40 \%$ of patients with ECE achieve a 5-year disease-specific survival (DSS) of $66 \%$ [6]. In this scenario, improved stratification approaches for high-risk patients with resected HNSCC are eagerly awaited. Histopathological factors may refine the prediction of outcomes in OSCC $[4,6]$, and molecular profiling holds great promise for predicting prognosis and devising tailored treatment approaches.

We have previously studied the hotspot mutation regions of 45 cancer-related genes with an ultra-deep $(>1000 \times)$ sequencing approach, using next-generation sequencing (NGS) of formalin-fixed paraffin-embedded (FFPE) samples obtained from 345 patients with resected OSCC [12]. The frequency of genetic variations in tumor suppressor genes identified in our study was largely similar to that observed in The Cancer Genome Atlas (TCGA) HNSCC dataset (containing whole-exome sequencing data of 279 tumors) [13]. However, we found a lesser degree of sequence variations for the CDKN2A ( $12.8 \%$ versus $22.6 \%$ in the TCGA data) and NOTCH1 ( $3.2 \%$ versus $18.6 \%$ in the TCGA data) genes. In contrast, several oncogenes (including potential drug targets) showed a 3-fold higher mutation rate in our sample than that in the TCGA dataset. Differences in exposure to known oral carcinogens, disease stage, ethnicity, or genetic background may at least in part explain such discrepancies. Importantly, we previously identified a genetic signature that independently predicted a poorer DFS [12]. Subsequently, in a previous study focussing on TP53, the most commonly mutated gene in HNSCC, we correlated the value of missense mutations affecting TP53 DNA-binding domain (DBD) (but not of the remaining TP53 mutations) with DSS [14].

In recent years, the paradigm of precision medicine in patients with malignancies has been gaining momentum. In the field of OSCC, the goal is to personalize prognostication and treatment strategies as a function of patient-specific somatic mutations and aberrant molecular pathways. In this scenario, we conducted a substudy of our original cohort subjected to NGS [12] by specifically focusing on patients with ECE $(n=201)$. Our main goal was to improve the prognostic stratification of high-risk patients by combining genetic information from NGS with traditional clinicopathological prognostic parameters.

\section{RESULTS}

\section{General characteristics of patients with and without ECE}

Between 1996 and 2011, we identified 345 OSCC patients. The median follow-up duration was 41.0 months (range: 1-214 months). In the subgroup of patients with ECE $(n=201)$, the median follow-up duration was 24.0 months (range: $0-179$ months). The general characteristics of patients with and without ECE are shown in Table 1 and Supplementary Table S1 (genes with a mutation rate of $<2 \%$ patients). Compared with patients without ECE, those with ECE showed a higher frequency of T34, N2b-c, Stage IV, poor differentiation, near margin, perineural and lymphatic invasion, and level 4-5 lymph node involvement. They also showed a deeper tumor invasion. The frequency of patients harboring genetic mutations in patients with and without ECE was $73.6 \%$ and $69.4 \%$, respectively $(P=0.394)$, with the mean number of mutations being $1.37 \pm 2.35$ and $1.01 \pm 1.13$, respectively $(P=0.056)$.

\section{Treatment modalities of patients with and without ECE}

The distribution of multimodal treatment in patients with and without ECE was as follows: surgery alone, $5 \%$ and $13 \%$; surgery plus radiotherapy, $20 \%$ and $54 \%$; and surgery plus CRT, $75 \%$ and $33 \%$, respectively. Of the 201 patients with ECE, 151 received adjuvant CRT. Most patients $(97 \%$; 146/151) received cisplatin-based chemotherapy. Three patients received gemcitabine, while two patients received other drugs. The dosage of cisplatin was $100 \mathrm{mg} / \mathrm{m}^{2}$ tri-weekly, $50 \mathrm{mg} / \mathrm{m}^{2}$ biweekly [15], or $30-40 \mathrm{mg} / \mathrm{m}^{2}$ weekly [16] in $29(19 \%), 50(33 \%)$, and 67 (44\%) patients, respectively. Eighty-two (56\%) patients received an accumulated cisplatin dose of $\geq 200 \mathrm{mg} / \mathrm{m}^{2}$ during adjuvant CRT. The radiation dose was $\geq 60 \mathrm{cGy}$ in 
Table 1: General characteristics of the study patients stratified according to the presence of neck lymph node extracapsular extension

\begin{tabular}{|c|c|c|c|c|c|c|c|c|c|c|c|}
\hline \multirow[b]{3}{*}{ Clinical variables } & \multicolumn{2}{|c|}{ ECE (-) } & \multicolumn{2}{|c|}{ ECE $(+)$} & \multirow[b]{3}{*}{$P$ value } & \multirow[b]{3}{*}{ Clinical variables } & \multirow{2}{*}{\multicolumn{2}{|c|}{$\begin{array}{l}\text { ECE (-) } \\
n=144\end{array}$}} & \multirow{2}{*}{\multicolumn{2}{|c|}{$\begin{array}{l}\text { ECE }(+) \\
n=201\end{array}$}} & \multirow[b]{3}{*}{$P$ value } \\
\hline & \multicolumn{2}{|c|}{$n=144$} & \multicolumn{2}{|c|}{$\mathrm{n}=\mathbf{2 0 1}$} & & & & & & & \\
\hline & $\mathrm{n}$ & $\%$ & $\mathrm{n}$ & $\%$ & & & $\mathrm{n}$ & $\%$ & $\mathrm{n}$ & $\%$ & \\
\hline Sex & & & & & 0.440 & Margin $<5 \mathrm{~mm}$ & 11 & 7.6 & 32 & 16.0 & 0.021 \\
\hline Male & 134 & 93.1 & 191 & 95 & & Depth $>10 \mathrm{~mm}$ & 88 & 61.1 & 143 & 71.1 & 0.051 \\
\hline Female & 10 & 6.9 & 10 & 5 & & Tumor invasion & & & & & \\
\hline Age, years & & & & & 0.761 & Bone & 27 & 18.8 & 44 & 21.9 & 0.477 \\
\hline Mean & \multicolumn{2}{|c|}{$49.4 \pm 10.5$} & \multicolumn{2}{|c|}{$49.8 \pm 11.3$} & & Skin & 12 & 8.3 & 25 & 12.4 & 0.224 \\
\hline Age $>70$ years & 8 & 5.6 & 8 & 4 & 0.605 & Perineural & 64 & 44.4 & 113 & 56.2 & 0.031 \\
\hline Cancer site & & & & & 0.552 & Vascular & 6 & 4.2 & 12 & 6.0 & 0.458 \\
\hline Tongue & 56 & 38.9 & 74 & 36.8 & & Lymphatic & 12 & 7.6 & 33 & 16.4 & 0.016 \\
\hline Mouth floor & 6 & 4.2 & 9 & 4.5 & & Level 4/5 lymph nodes & 4 & 2.8 & 23 & 11.4 & 0.004 \\
\hline Lip & 1 & 0.7 & 1 & 0.5 & & HPV & & & & & 0.526 \\
\hline Buccal & 52 & 36.1 & 80 & 39.8 & & None & 115 & 88.5 & 159 & 85.0 & \\
\hline Gum & 17 & 11.8 & 27 & 13.4 & & Type 16,18 & 15 & 11.5 & 27 & 14.4 & \\
\hline Hard palate & 5 & 3.5 & 1 & 0.5 & & Other type $^{\mathrm{a}}$ & 0 & 0 & $1 \mathrm{~b}$ & 0.5 & \\
\hline Retromolar & 7 & 4.9 & 9 & 4.5 & & Genetic variables & $\mathrm{n}$ & $\%$ & $\mathrm{n}$ & $\%$ & $P$ value \\
\hline Tumor status & & & & & 0.084 & Presence of mutations & 100 & 69.4 & 148 & 73.6 & 0.394 \\
\hline 1 & 10 & 6.9 & 6 & 3.0 & & $\begin{array}{l}\text { Number of mutations } \\
\text { (mean) }\end{array}$ & 1.01 & $=1.13$ & 1.37 & 2.35 & 0.056 \\
\hline 2 & 64 & 44.4 & 73 & 36.3 & & TP53 & 78 & 54.2 & 123 & 61.2 & 0.192 \\
\hline 3 & 27 & 18.8 & 43 & 21.4 & & TP53 DBD missense & 59 & 42.1 & 98 & 50.8 & 0.119 \\
\hline 4 & 43 & 29.9 & 79 & 39.3 & & mutations $(\mathrm{n}=333)$ & & & & & \\
\hline Lymph node status & & & & & $<0.001$ & CDKN2A & 15 & 10.4 & 23 & 11.4 & 0.764 \\
\hline N1 & 91 & 63.2 & 32 & 15.9 & & PIK3CA & 12 & 8.3 & 23 & 11.4 & 0.346 \\
\hline $\mathrm{N} 2 \mathrm{a}$ & 0 & 0 & 3 & 1.5 & & HRAS & 9 & 6.3 & 20 & 10.0 & 0.222 \\
\hline $\mathrm{N} 2 \mathrm{~b}$ & 48 & 33.3 & 138 & 68.7 & & BRAF & 4 & 2.8 & 7 & 3.5 & 0.768 \\
\hline $\mathrm{N} 2 \mathrm{c}$ & 5 & 3.5 & 28 & 13.9 & & EGFR & 4 & 2.8 & 6 & 3.0 & 1.000 \\
\hline Stage & & & & & $<0.001$ & FGFR3 & 1 & 0.7 & 6 & 3.0 & 0.246 \\
\hline III & 63 & 43.8 & 22 & 10.9 & & SMAD4 & 1 & 0.7 & 6 & 3.0 & 0.246 \\
\hline IV & 81 & 56.3 & 179 & 89.1 & & KDR & 2 & 1.4 & 5 & 2.5 & 0.704 \\
\hline Differentiation & & & & & 0.062 & MET & 1 & 0.7 & 5 & 2.5 & 0.407 \\
\hline Well & 31 & 21.5 & 32 & 15.9 & & ERBB4 & 0 & 0 & 4 & 2.0 & 0.143 \\
\hline Moderate & 97 & 67.4 & 129 & 64.2 & & KIT & 0 & 0 & 4 & 2.0 & 0.143 \\
\hline Poor & 16 & 11.1 & 40 & 19.9 & & ABL1 & 3 & 2.1 & 2 & 1.0 & 0.653 \\
\hline $\mathrm{ECE} \geq 4$ & & & 35 & 17.4 & & SMO & 3 & 2.1 & 1 & 0.5 & 0.312 \\
\hline
\end{tabular}

CRT, chemoradiotherapy; DBD, DNA-binding domain; ECE, extracapsular extension; HPV, human papilloma virus.

a HPV type 11

${ }^{b}$ Genes with a mutation rate of $\geq 2 \%$ patients in $\mathrm{ECE}(+)$ or $\operatorname{ECE}(-)$ were included in the analysis.

$147(97.3 \%)$ patients.

\section{Clinical outcomes in patients with and without ECE}

The 5-year clinical outcomes in patients with and without ECE were as follows: LRF rates of $43 \%$ and $36 \%$ $(P=0.041)$; distant metastases (DM) rates of $39 \%$ and $12 \%,(P<0.001)$; DSS rates of $47 \%$ and $70 \%(P<0.001)$; and overall survival (OS) rates of $37 \%$ and $58 \%(P<$
$0.001)$, respectively.

\section{Prognostic factors in patients with ECE}

Univariate (Supplementary Table S2) and multivariate (Table 2) analyses were used to identify prognostic factors in patients with ECE. In multivariate analysis, adjuvant CRT showed an independent positive impact on all clinical outcomes (LRF, DM, DSS, and OS). Conversely, $\geq 4$ ECEs showed a detrimental effect on 
Table 2: Multivariate analysis ${ }^{a}$ in patients stratified according to the presence of neck lymph node extracapsular extension and use of adjuvant therapy

\begin{tabular}{|c|c|c|c|c|c|}
\hline & & Locoregional control & Distant metastasis & Disease specific survival & Overall survival \\
\hline & n (\%) & $P$ value, HR $(95 \%$ CI $)$ & $P$ value, HR $(95 \%$ CI $)$ & $P$ value, HR (95\% CI) & $P$ value, HR $(95 \% \mathrm{CI})$ \\
\hline \multicolumn{6}{|c|}{ Patients with ECE $(n=201)$} \\
\hline Adjuvant CRT & $151(75.1)$ & $0.000,0.32(0.19-0.56)$ & $0.002,0.42(0.24-0.73)$ & $0.000,0.28(0.17-0.43)$ & $0.000,0.26(0.17-0.39)$ \\
\hline $\mathrm{ECE} \geq 4$ & $35(17.4)$ & & $0.000,3.11(1.79-5.39)$ & $0.002,2.17(1.34-3.52)$ & $0.000,2.55(1.58-4.12)$ \\
\hline pT4 & $79(39.3)$ & & & $0.048,2.22(1.00-4.90)$ & $0.036,1.99(1.04-3.81)$ \\
\hline $\mathrm{pN} 2$ & $169(84.1)$ & $0.008,3.18(1.35-7.44)$ & & & \\
\hline Margin $<5 \mathrm{~mm}$ & $32(15.9)$ & & $0.011,2.16(1.19-3.94)$ & $0.013,1.90(1.14-3.15)$ & \\
\hline \multicolumn{6}{|l|}{ Tumor invasion } \\
\hline Skin & $25(12.4)$ & & & & $0.007,2.15(1.22-3.76)$ \\
\hline Lymph duct & & & & & $0.019,0.53(0.31-0.90)$ \\
\hline $\begin{array}{l}\text { Level 4-5 lymph node } \\
\text { involvement }\end{array}$ & $23(11.4)$ & $0.000,3.59(1.89-6.83)$ & & & \\
\hline CDKN2A mutations & $23(11.4)$ & & & $0.036,1.97(1.04-3.74)$ & $0.002,2.29(1.35-3.87)$ \\
\hline HRAS mutations & $20(10.0)$ & & $0.000,3.87(1.98-7.57)$ & $0.002,2.60(1.41-4.81)$ & \\
\hline \multicolumn{6}{|c|}{ Patients with ECE and adjuvant CRT $(n=151)$} \\
\hline $\mathrm{ECE} \geq 4$ & $25(16.6)$ & & $0.000,3.65(1.77-6.38)$ & $0.005,2.26(1.27-4.03)$ & $0.004,2.19(1.29-3.72)$ \\
\hline pT4 & $60(39.7)$ & $0.019,1.96(1.12-3.45)$ & & & $0.004,1.88(1.22-2.91)$ \\
\hline Margin $<5 \mathrm{~mm}$ & $25(16.8)$ & & & $0.012,2.14(1.18-3.88)$ & \\
\hline Differentiation & & & $0.052,1.90(0.99-3.63)$ & & \\
\hline $\begin{array}{l}\text { Level 4-5 lymph node } \\
\text { involvement }\end{array}$ & $18(11.9)$ & $0.001,3.36(1.67-6.78)$ & & & \\
\hline CDKN2A mutations & $19(12.6)$ & & & & $0.001,2.62(1.45-4.72)$ \\
\hline HRAS mutations & $12(7.9)$ & & $0.001,3.83(1.69-8.68)$ & $0.003,3.11(1.46-6.62)$ & \\
\hline \multicolumn{6}{|c|}{ Patients treated with CRT and 1-3 nodes with ECE $(n=126)$} \\
\hline $\operatorname{Margin}(<5 \mathrm{~mm})$ & $18(14.3)$ & $0.022,2.48(1.13-5.44)$ & & $0.011,2.53(1.24-5.16)$ & $0.015,2.21(1.16-4.20)$ \\
\hline $\begin{array}{l}\text { Level } 4 / 5 \text { lymph node } \\
\text { involvement }\end{array}$ & $11(8.7)$ & $0.048,2.49(1.00-6.16)$ & & & \\
\hline HRAS mutations & $11(8.7)$ & & $0.001,4.33(1.77-10.60)$ & $0.021,2.67(1.15-6.16)$ & \\
\hline $\begin{array}{l}\text { TP53 DBD missense } \\
\text { mutations }\end{array}$ & $63(50.0)$ & & & $0.044,1.89(1.01-3.52)$ & $0.003,2.16(1.30-3.57)$ \\
\hline
\end{tabular}

a Genes with a mutation rate of $\geq 2 \%$ patients were included in the analysis

CI, confidence interval; CRT, chemoradiotherapy; DBD, DNA-binding domain; ECE, extracapsular extension; HR, hazard ratio.

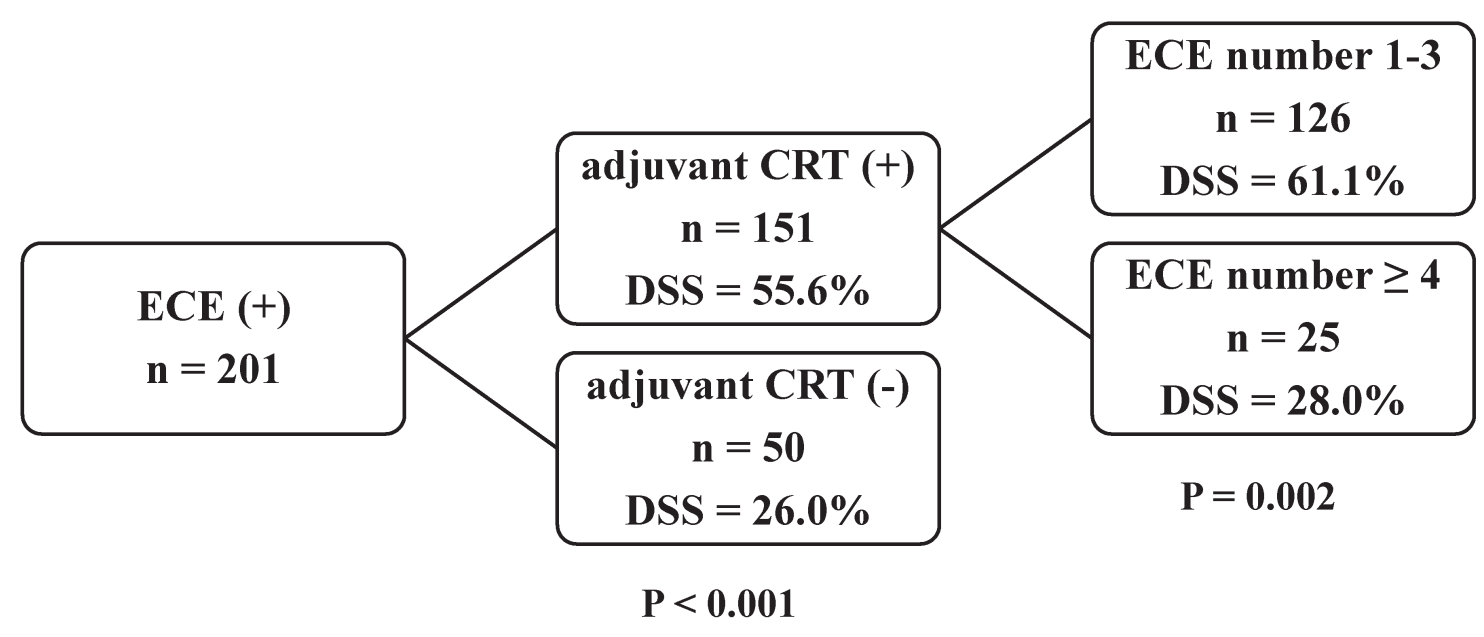

Figure 1: Classification tree derived from recursive partitioning analysis for disease-specific survival. Abbreviations: $\boldsymbol{C R T}$, chemoradiotherapy; DSS, disease-specific survival; $\boldsymbol{E C E}$, extracapsular extension. 
Table 3: Clinical outcomes in different patient subgroups

\begin{tabular}{|c|c|c|c|c|c|c|c|c|c|}
\hline & & \multicolumn{2}{|c|}{ Locoregional failure } & \multicolumn{2}{|c|}{ Distant failure } & \multicolumn{2}{|c|}{ Disease-specific survival } & \multicolumn{2}{|c|}{ Overall survival } \\
\hline & n & \begin{tabular}{|l|}
$5-y r$ rate \\
$(\%)$
\end{tabular} & \begin{tabular}{|c|} 
Survival $^{\mathrm{a}}$ \\
(months)
\end{tabular} & \begin{tabular}{|l|}
$5-y r$ \\
$(\%)$
\end{tabular} & \begin{tabular}{|l|} 
Survival \\
(months)
\end{tabular} & \begin{tabular}{|l|}
$5-y r$ \\
$(\%)$
\end{tabular} & \begin{tabular}{|l|} 
Survival \\
(months)
\end{tabular} & $\begin{array}{l}\text { 5-yr rate } \\
(\%) \\
\end{array}$ & \begin{tabular}{|l|} 
Survival \\
(months)
\end{tabular} \\
\hline LN status & 345 & & & & & & & & \\
\hline $\operatorname{ECE}(-)$ & 144 & 36 & NR & 12 & NR & 70 & NR & 58 & 105 \\
\hline $\mathrm{ECE}(+)$ & 201 & \begin{tabular}{|l|l|}
43 \\
\end{tabular} & NR & 39 & NR & 47 & 35 & 37 & 24 \\
\hline$P$ value, $\mathrm{HR}(95 \% \mathrm{CI})$ & & \multicolumn{2}{|c|}{$0.044,1,45(1.01-2.08)$} & \multicolumn{2}{|c|}{$0.000,3.50(2.08-5.88)$} & \multicolumn{2}{|c|}{$0.000,2.31(1.61-3.30)$} & \multicolumn{2}{|c|}{$0.001,1.86(1.39-2.48)$} \\
\hline Presence of ECE & 201 & & & & & & & & \\
\hline $\mathrm{CRTb}(+)$ & 151 & 39 & NR & 33 & NR & 55 & NR & 45 & 44 \\
\hline CRT (-) & 50 & \begin{tabular}{|l|l|}
58 \\
\end{tabular} & 11 & 60 & 14 & 21 & 9 & 14 & 9 \\
\hline$P$ value, $\mathrm{HR}(95 \% \mathrm{CI})$ & & \multicolumn{2}{|c|}{$0.001,0.44(0.27-0.71)$} & \multicolumn{2}{|c|}{$0.001,0.42(0.26-0.70)$} & \multicolumn{2}{|c|}{$<0.001,0.34(0.23-0.52)$} & \multicolumn{2}{|c|}{$<0.001,0.37(0.25-0.53)$} \\
\hline $\begin{array}{l}\text { Presence of ECE and history of } \\
\text { CRT }\end{array}$ & 151 & & & & & & & & \\
\hline ECE $1-3$ & 126 & 34 & NR & 28 & NR & 60 & NR & 49 & 70 \\
\hline $\mathrm{ECE} \geq 4$ & 25 & 67 & 31 & 62 & 18 & 25 & 14 & 20 & 13 \\
\hline$P$ value, $\mathrm{HR}(95 \% \mathrm{CI})$ & & \multicolumn{2}{|c|}{$0.026,2.10(1.09-4.02)$} & \multicolumn{2}{|c|}{$0.002,2.64(1.41-4.94)$} & \multicolumn{2}{|c|}{$0.001,2.42(1.40-4.16)$} & \multicolumn{2}{|c|}{$0.005,2.04(1.24-3.37)$} \\
\hline $\begin{array}{l}\text { Presence of ECE 1-3 and history } \\
\text { of CRT }\end{array}$ & 126 & & & & & & & & \\
\hline Margin $\geq 5 \mathrm{~mm}$ & 108 & 30 & NR & & & 63 & NR & 52 & 79 \\
\hline Margin $<5 \mathrm{~mm}$ & 18 & 66 & 33 & & & 42 & 14 & 33 & 14 \\
\hline$P$ value, HR $(95 \% \mathrm{CI})$ & & \multicolumn{2}{|c|}{$0.007,2.81(1.32-5.98)$} & & & \multicolumn{2}{|c|}{$0.039,2.08(1.04-4.18)$} & \multicolumn{2}{|c|}{$0.065,1.79(0.96-3.34)$} \\
\hline Level 4/5 LN (-) & 115 & \begin{tabular}{|l|}
31 \\
\end{tabular} & NR & & & & & & \\
\hline Level 4/5 LN (+) & 11 & \begin{tabular}{|l|l|}
71 \\
\end{tabular} & 8 & & & & & & \\
\hline$P$ value, HR $(95 \% \mathrm{CI})$ & & \multicolumn{2}{|c|}{$0.002,3.62(1.59-8.23)$} & & & & & & \\
\hline HRAS mutations $(-)$ & 115 & & & 25 & NR & 63 & NR & & \\
\hline HRAS mutations $(+)$ & 11 & & & 55 & 10 & 36 & 14 & & \\
\hline$P$ value, $\mathrm{HR}(95 \% \mathrm{CI})$ & & & & \multicolumn{2}{|c|}{$0.007,3.41(1.40-8.29)$} & \multicolumn{2}{|c|}{$0.024,2.52(1.13-5.62)$} & & \\
\hline TP53 DBD missense mutations (-) & 60 & & & & & 71 & NR & 61 & NR \\
\hline TP53 DBD missense mutations $(+)$ & 63 & & & & & 52 & NR & 39 & 42 \\
\hline$P$ value, $\mathrm{HR}(95 \% \mathrm{CI})$ & & & & & & \multicolumn{2}{|c|}{$0.025,1.97(1.09-3.59)$} & \multicolumn{2}{|c|}{$0.007,1.97(1.20-3.22)$} \\
\hline
\end{tabular}

${ }^{a}$ Median.

CI, confidence interval; CRT, chemoradiotherapy; DBD, DNA-binding domain; ECE, extracapsular extension; HR, hazard ratio; LN, lymph node; NR, not reached; yr, year.

DM, DSS, and OS (but not LRF). Additionally, both $<5$ mm margin and HRAS mutation were adverse prognostic factors for DM and DSS. The presence of pT4 disease and CDKN2A mutations negatively affected DSS and OS. High-risk HPV types (16/18) and other genetic mutations did not show an independent association with clinical outcomes.

\section{Recursive partitioning analysis}

Patients were classified with the use of recursive partitioning analysis (RPA). To this aim, DSS was considered as the dependent variable, whereas independent risk factors identified in multivariate analyses served as predictors/covariates. The classification tree obtained by applying the RPA method identified adjuvant CRT and the number of nodes with ECE as the first and second splitting variables, respectively (Figure 1). The 5-year clinical outcomes of patients who underwent adjuvant CRT versus those who did not were as follows: LRF rates of 39\% and 58\% $(P=0.001)$; DM rates of $33 \%$ and $60 \%$ $(P=0.001)$; DSS rates of $55 \%$ and $21 \%(P<0.001)$; and
OS rates of $45 \%$ and $14 \%(P<0.001)$, respectively (Table $3)$. Patients who were treated with adjuvant CRT were further stratified according to the number of ECEs. The 5-year clinical outcomes of patients with 1-3 versus those with $\geq 4$ ECEs were as follows: LRF rates of $34 \%$ and $67 \%(P=0.026)$; DM rates of $28 \%$ and $62 \%(P=0.002)$; DSS rates of $60 \%$ and $25 \%(P=0.001)$; and OS rates of $49 \%$ and $20 \%(P=0.005)$, respectively.

\section{Multivariate analysis in specific subgroups}

In the subgroup of patients who underwent CRT and exhibited 1-3 nodes with ECE (i.e., those with a favorable expected prognosis), we identified the following adverse prognostic factors in multivariate analysis (Table 2): 1) < $5 \mathrm{~mm}$ margin for locoregional failure (66\% versus $30 \%$, $P=0.007)$ and DSS (42\% versus $63 \%, P=0.039) ; 2)$ HRAS mutations for distant failure (55\% versus $25 \%$, $P=0.007)$ and DSS (36\% versus $63 \%, P=0.024)$; and 3$)$ TP53 DNA-binding domain missense mutations for DSS (52\% versus $71 \%, P=0.025)$ and OS $(39 \%$ versus $61 \%$, $P=0.007)$. The 5-year DSS and OS rates of patients who 
had $\geq 4$ nodes with ECE were $25 \%$ and $20 \%$, respectively. Both, the small sample size of this patient subgroup ( $n$ $=25$ ) and their dismal outcomes precluded a meaningful multivariate analysis. The clinical outcomes of patients stratified according to the presence of ECE, the use of CRT, and the number of nodes with ECE are shown in Table 3 and Figure 2.

\section{DISCUSSION}

In our study, ECE incidence correlated with worse outcomes in patients with resected OSCC. The 5-year OS rates of patients with and without ECE were $37 \%$ and $58 \%$, respectively. However, adjuvant CRT has been reported to improve LRF, DSS, and OS rates, but not that of DM [8-10]. Distant failure occurs more frequently in patients with ECE [4, 17] and buccal cancer [18]. It is noteworthy that the benefit of adjuvant CRT in our high-risk cohort was evident for all time-to-event endpoints, including DM (Table 3). We acknowledge that a comparison of patients who received adjuvant CRT versus those who did not should be interpreted cautiously because of selection bias. Indeed, the use of adjuvant CRT in our study was driven by the patient's general conditions and the physician's

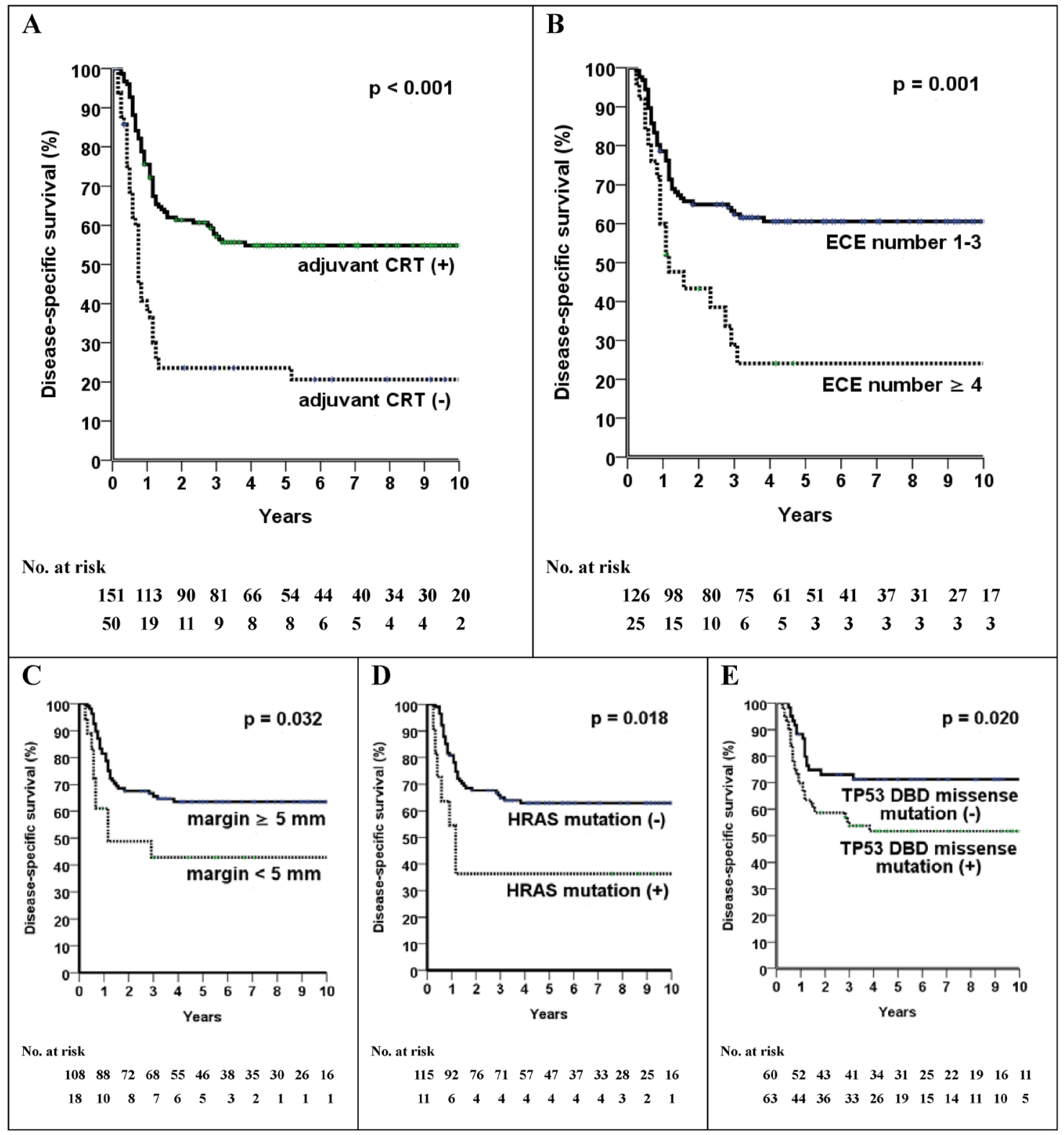

Figure 2: Disease-specific survival stratified according to the use of CRT (A), number of nodes with ECE (B), and grouping of risk factors in patients treated with CRT for harboring 1-3 nodes with ECE (C, D, E). Abbreviations: $\boldsymbol{C R T}$, chemoradiotherapy; $\boldsymbol{D B D}$, DNA-binding domain; $\boldsymbol{E} \boldsymbol{C}$, extracapsular extension. 
discretion. The clinical and genomic characteristics of patients with and without CRT were well balanced, the only exception being a higher frequency of patients with a $>10 \mathrm{~mm}$ depth of tumor invasion in those who did not receive CRT $(65.6 \%$ versus $88.0 \%$, respectively, $P=$ 0.002; Supplementary Table S2). However, the depth of invasion was not an independent predictor of either DSS or DM in multivariate analysis (Table 2). Based on our results, we believe that adjuvant CRT has a positive impact in patients with ECE in terms of all clinical endpoints (i.e., LRF, DSS, OS, and DM). Unfortunately, the outcomes of patients with ECE remain poor even with the use of adjuvant CRT.

Several studies have focused on the prognostic value of ECE extent using different methodological approaches including microscopic versus macroscopic ECE [19], a pathological ECE grading system [20], the combination of ECE with other prognostic parameters [6], and the number of nodes showing ECE [4, 21-24]. However, previous reports were heterogeneous in terms of ECE status (positive versus negative) [4,21,24], primary tumor site (e.g., inclusion of oropharyngeal cancer) [24], and type of adjuvant therapy (RT versus CRT) [4, 21, 24]. The presence of more than one node with ECE is the variable most consistently associated with clinical outcomes in previous studies [4, 21, 24]. With RT being the most commonly used adjuvant therapy, a 5-year survival of < $20 \%$ has been reported for patients with an ECE number $>1[4,21,24]$. In the current study, 151 patients who received adjuvant CRT due to the presence of ECE were included. Their 5-year OS rates stratified according to the number of nodes with ECE $\geq 2, \geq 3$, and $\geq 4$ were $44 \%$, $43 \%$, and $20 \%$, respectively. These findings indicate that modern adjuvant CRT may mitigate the adverse prognostic significance of the number of lymph nodes with ECE. With the future goal of implementing precision medicine, it is paramount to provide a molecular refinement of prognosis for patients who have 1-3 nodes with ECE and lack of response to adjuvant CRT. Multivariate analysis (Table 2) revealed the adverse prognostic impact of a $<5$ $\mathrm{mm}$ margin on LRF and DSS; HRAS mutations on DM and DSS; and TP53 DBD missense mutations on DSS and OSS. Importantly, the outcome of patients without such risk factors was similar to that of subjects without ECE (Table 3).

TP53 is the most commonly mutated gene in HNSCC $(60 \%-80 \%$ cases $)[13,25]$, with its mutations being associated with an unfavorable prognosis [26-28]. Poeta et al. [27] found an association between disruptive TP53 mutations and decreased OS in 420 patients with resected HNSCC enrolled between 1996 and 2002. In their study, 180 patients with OSCC were included, but no data were available regarding their ECE status and adjuvant CRT. The mutations that introduced a stop codon or nonconservative mutations occurring in specific DBDs were defined as disruptive. However, disruptive mutations include two biologically different subtypes, namely 1) truncating mutations associated with a loss of tumor suppressive activity, and 2) DBD missense mutations. DBD missense mutations can result in a gain of function [29] and have been previously associated with decreased DSS in OSCC patients [14]. To the best of our knowledge, this is the first report where the adverse prognostic significance of TP53 DBD missense mutations in patients treated with adjuvant CRT and showed 1-3 nodes with ECE. As discussed above, patients showing 1-3 nodes with ECE are expected to benefit most from adjuvant CRT. Our current observations are in line with previous data reporting an association between TP53 mutations, platinum resistance, and unfavorable outcomes [28, 30]. The impact of TP53 DBD missense mutations on OS $(P=0.003)$ seems greater than that on DSS. However, the percentages of patients with TP53 DBD missense mutations who survived, died of disease-specific causes, and died of competing causes were $27.6 \%, 57.1 \%$, and $15.3 \%$, respectively. The corresponding figures in patients without TP53 DBD missense mutations were $41.1 \%$, $43.2 \%$, and $15.8 \%$, respectively. Consequently, the observed effect of TP53 DBD missense mutations on OS seems to be driven mainly by disease-specific mortality.

The RAS gene family has been repeatedly shown to be involved in the molecular pathogenesis of OSCC. Specifically, mean mutation rates of $11.2 \%, 4.5 \%$, and $0.3 \%$ have been reported for the HRAS, KRAS, and NRAS genes, respectively [31]. HRAS mutations are common in Asian patients who live in areas where chewing betel quid is an endemic habit [31]. The RAS pathway mediates cellular responses to growth signals and is frequently deregulated in oral cancer. In addition, HRAS mutations have an adverse prognostic impact in terms of PFS and OS rates [32]. In our patients with ECE, the mutation rates of the HRAS, KRAS, and NRAS genes were $10 \%, 1.5 \%$, and $0 \%$, respectively. Although the locoregional failure rates of patients with and without HRAS mutations were similar ( $38 \%$ and $35 \%$, respectively; $P=0.785$ ), the distant failure rate was significantly higher in the former group $(65 \%$ versus $32 \%$, respectively; $P=0.003$ ). Differently from HRAS mutations that showed an adverse impact on distant failure, the detrimental effect of $<5 \mathrm{~mm}$ margin was in terms of locoregional failure.

In patients with and without CDKN2A mutations, the rates of TP53 DBD missense mutations were 73.7\% and $48.3 \%$, respectively $(P=0.051)$. In addition, the frequencies of HRAS mutations were $30.4 \%$ and $7.3 \%$, respectively $(P=0.000)$. The coexistence of CDKN2A mutations with other prognostically adverse genetic variations may explain why the significance of the former on DSS and OS (which was present in the cohort of 201 patients harboring ECE) was not replicated when the analysis was based on the number of nodes with ECE.

Patients with $\geq 4$ nodes with ECE showed a dismal prognosis despite the implementation of adjuvant therapy. 
Consequently, the clinical management of high-risk patients (i.e., patients with an ECE number $\geq 4$ or $1-3$ nodes with ECE and concomitant risk factors) needs to be improved. To achieve this goal, potential future directions include early diagnosis of relapses [33], pre-RT early systemic therapy $[34,35]$, the combination of different chemotherapy agents with RT [36], the use of altered fractionation/dose escalation RT [37], and genotype-driven targeted therapies [32].

Some caveats of our report merit consideration. First, our study has a retrospective design that makes it prone to selection bias and the presence of potential confounders that were not accounted for. Another potential limitation lies in the identification of the optimal cut-off for the number of nodes with ECE in relation to adverse outcomes. The cut-off of 4 used for this study needs further validation in independent studies. Finally, our observations should be viewed as exploratory and hypothesis generating. Conversely, our study also has significant strengths. Accordingly, this is the largest cohort of homogenously staged, treated, and followed-up OSCC patients with ECE treated with state-of-the-art adjuvant CRT.

In conclusion, our data demonstrate that OSCC is a mutationally heterogeneous malignancy. The combined assessment of the tumor mutation spectrum with traditional clinicopathological risk factors may help refining the prediction of specific clinical outcomes. Further improvements in sequencing techniques and independent validation of our results in distinct cohorts will be necessary to implement precision medicine in resected OSCC patients harboring ECE.

\section{PATIENTS AND MATERIALS}

\section{Patients}

This study includes a subanalysis of a previously described cohort [12] consisting of 345 patients with treatment-naïve, resected OSCC. All participants showed evidence of nodal disease and tumor samples were available (which were analyzed by ultra-deep targeted sequencing as previously described [12]). The subgroup of patients with evidence of ECE $(n=201$; diagnosed by microscopic visualization of tumor penetration into the lymph node capsule) was the main focus of the study. Ethical approval was granted by the Institutional Review Board of the Chang Gung Memorial Hospital (CGMH 101-4457B). Due to the retrospective nature of the study, the need for patient consent was waived.

\section{Treatment approach and follow-up schedule}

Although all patients with ECE were encouraged to undergo adjuvant CRT, its final use depended on both, patient's willingness and physician's discretion. The most commonly used chemotherapy regimens consisted of cisplatin $100 \mathrm{mg} / \mathrm{m}^{2}$ tri-weekly, $50 \mathrm{mg} / \mathrm{m}^{2}$ biweekly [15], or 30-40 mg/m² weekly [16]. An adjuvant RT dose of 66 Gy (given in 33 fractions) was generally administered within 6 weeks of surgical resection. After the completion of therapy, patients underwent a follow-up consisting of physical examination every 3 months for the first two years, every 4 to 6 months for the third year, and on an annual basis thereafter. Patients underwent magnetic resonance imaging (MRI)/computed tomography (CT), and/or ${ }^{18} \mathrm{~F}$-fluorodeoxyglucose-positron emission tomography $\left({ }^{18} \mathrm{~F}-\mathrm{FDG}-\mathrm{PET}\right)$ at 3 months after the completion of therapy, and subsequently at 12,18 , and 24 months. Thereafter, symptom-directed imaging was performed. Cases with suspected relapse unscheduled assessments.

\section{Mutation analysis}

The hotspot mutation regions of 45 cancer-related genes were examined using NGS with an ultra-deep $(>1000 \times)$ sequencing approach in FFPE, primary tumor samples as previously described [12]. We examined the following 29 oncogenes and 16 tumor suppressor genes (TSG): ABL1, AKT1, ALK, APC, ATM, BRAF, CDH1, CDKN2A, CSF1R, CTNNB1, EGFR, ERBB2, ERBB4, FBXW7, FGFR1, FGFR2, FGFR3, FLT3, GNAS, HNF1A, HRAS, IDH1, JAK3, KDR, KIT, KRAS, MET, MLH1, MPL, NOTCH1, NPM1, NRAS, PDGFRA, PIK3CA, PTEN, PTPN11, RB1, RET, SMAD4, SMARCB1, SMO, SRC, STK11, TP53, and VHL. In a separate study, we examined the value of missense mutations affecting the TP53 DBD (but not of the remaining TP53 mutations) for the prediction of DSS [14]. HPV infections were diagnosed using HPV L1 gene PCR. In patients who tested positive, the HPV L1 gene was genotyped using an HPV Blot kit (EasyChipTM, King Car Ltd., Yilan, Taiwan) that can differentiate between 39 different HPV types [38].

\section{Study endpoints}

The study endpoints included LRF, DM, DSS, and OS. All time-to-event endpoints were calculated from the date of surgery to the date of the event of interest (or censored on the date of the last follow-up). 


\section{Data analysis}

Categorical data were compared using Fisher's exact test $(2 \times 2$ tables). Continuous variables were examined with independent-sample Student's $t$-test. Univariate analysis was performed by logistic regression. KaplanMeier plots (log-rank tests) were used to summarize the course of time-to-event data. Multivariate Cox proportional hazards models were used to identify the independent predictors of clinical outcomes. Recursive partitioning analysis (RPA) was then used to classify patients into successively more homogeneous prognostic groups based on multiple input variables. All calculations were performed using the SPSS statistical package, version 18.0 (SPSS Inc., Chicago, IL, USA). $P$ values $<$ 0.05 (two-tailed) were considered statistically significant.

\section{ACKNOWLEDGMENTS}

We thank the Linkou Chang Gung Memorial Hospital Cancer Center databank and the Bioinformatics Core and Genomic Core of the Molecular Medicine Research Center at Chang Gung University for their support and contribution to this study.

\section{CONFLICTS OF INTEREST}

Shu-Jen Chen is an employee of ACT Genomics.

\section{GRANT SUPPORT}

This study was financially supported by grants NMRPG3B0403, CIRPG1E0012, CMRPG3C0833, and CMRPG3D1071 from the Chang Gung Memorial Hospital at Linkou (Taiwan).

\section{REFERENCES}

1. Jemal A, Bray F, Center MM, Ferlay J, Ward E, Forman D. Global cancer statistics. CA Cancer J Clin. 2011; 61:69-90.

2. Bureau of Health Promotion DoH, the Executive Yuan, Taiwan, R.O.C. Cancer Registry Annual Report 2012. In; 2015.

3. Myers JN, Greenberg JS, Mo V, Roberts D. Extracapsular spread. A significant predictor of treatment failure in patients with squamous cell carcinoma of the tongue. Cancer. 2001; 92:3030-6.

4. Shaw RJ, Lowe D, Woolgar JA, Brown JS, Vaughan ED, Evans C, Lewis-Jones H, Hanlon R, Hall GL, Rogers SN. Extracapsular spread in oral squamous cell carcinoma. Head Neck. 2010; 32:714-22.

5. Jan JC, Hsu WH, Liu SA, Wong YK, Poon CK, Jiang RS, Jan JS, Chen IF. Prognostic factors in patients with buccal squamous cell carcinoma: 10-year experience. J Oral
Maxillofac Surg. 2011; 69:396-404.

6. Liao CT, Lee LY, Huang SF, Chen IH, Kang CJ, Lin CY, Fan KH, Wang HM, Ng SH, Yen TC. Outcome analysis of patients with oral cavity cancer and extracapsular spread in neck lymph nodes. Int J Radiat Oncol Biol Phys. 2011; 81:930-7.

7. Dunne AA, Muller HH, Eisele DW, Kessel K, Moll R, Werner JA. Meta-analysis of the prognostic significance of perinodal spread in head and neck squamous cell carcinomas (HNSCC) patients. Eur J Cancer. 2006; 42:1863-8.

8. Bernier J, Domenge C, Ozsahin M, Matuszewska K, Lefebvre JL, Greiner RH, Giralt J, Maingon P, Rolland F, Bolla $\mathrm{M}$, et al. Postoperative irradiation with or without concomitant chemotherapy for locally advanced head and neck cancer. N Engl J Med. 2004; 350:1945-52.

9. Cooper JS, Pajak TF, Forastiere AA, Jacobs J, Campbell BH, Saxman SB, Kish JA, Kim HE, Cmelak AJ, Rotman $M$, et al. Postoperative concurrent radiotherapy and chemotherapy for high-risk squamous-cell carcinoma of the head and neck. N Engl J Med. 2004; 350:1937-44.

10. Bernier J, Cooper JS, Pajak TF, van Glabbeke M, Bourhis J, Forastiere A, Ozsahin EM, Jacobs JR, Jassem J, Ang KK, et al. Defining risk levels in locally advanced head and neck cancers: a comparative analysis of concurrent postoperative radiation plus chemotherapy trials of the EORTC (\#22931) and RTOG (\# 9501). Head Neck. 2005; 27:843-50.

11. Cooper JS, Zhang Q, Pajak TF, Forastiere AA, Jacobs J, Saxman SB, Kish JA, Kim HE, Cmelak AJ, Rotman M, et al. Long-term follow-up of the RTOG 9501/intergroup phase III trial: postoperative concurrent radiation therapy and chemotherapy in high-risk squamous cell carcinoma of the head and neck. Int J Radiat Oncol Biol Phys. 2012; 84:1198-205.

12. Chen SJ, Liu H, Liao CT, Huang PJ, Huang Y, Hsu A, Tang P, Chang YS, Chen HC, Yen TC. Ultra-deep targeted sequencing of advanced oral squamous cell carcinoma identifies a mutation-based prognostic gene signature. Oncotarget. 2015; 6:18066-80. doi: 10.18632/ oncotarget. 3768 .

13. Cancer Genome Atlas N. Comprehensive genomic characterization of head and neck squamous cell carcinomas. Nature. 2015; 517:576-82.

14. Lapke N, Lu YJ, Liao CT, Lee LY, Lin CY, Wang HM, $\mathrm{Ng} \mathrm{SH}$, Chen SJ, Yen TC. Missense Mutations in the TP53 DNA-Binding Domain Predict Outcomes in Patients with Advanced Oral Cavity Squamous Cell Carcinoma. Oncotarget. 2016; 7:44194-44210. doi: 10.18632/ oncotarget.9925.

15. Wang HM, Hsu CL, Heish CH, Fan KH, Lin CY, Chang TC, Huang SF, Chen IH, Liao CT, Ng SK. Concurrent Chemoradiotherapy Using Cisplatin, Tegafur and Leucovorin for Advanced Squamous Cell Carcinoma of the Hypopharynx and Oropharynx. Biomed J. 2014; 37:133140. 
16. D'Cruz A, Lin T, Anand AK, Atmakusuma D, Calaguas MJ, Chitapanarux I, Cho BC, Goh BC, Guo Y, Hsieh $\mathrm{WS}$, et al. Consensus recommendations for management of head and neck cancer in Asian countries: a review of international guidelines. Oral Oncol. 2013; 49:872-7.

17. Oosterkamp S, de Jong JM, Van den Ende PL, Manni JJ, Dehing-Oberije C, Kremer B. Predictive value of lymph node metastases and extracapsular extension for the risk of distant metastases in laryngeal carcinoma. Laryngoscope. 2006; 116:2067-70.

18. Liao CT, Huang SF, Chen IH, Kang CJ, Lin CY, Fan KH, Wang HM, Ng SH, Hsueh C, Lee LY, et al. Tongue and buccal mucosa carcinoma: is there a difference in outcome? Ann Surg Oncol. 2010; 17:2984-91.

19. Ferlito A, Rinaldo A, Devaney KO, MacLennan K, Myers JN, Petruzzelli GJ, Shaha AR, Genden EM, Johnson JT, de Carvalho MB, et al. Prognostic significance of microscopic and macroscopic extracapsular spread from metastatic tumor in the cervical lymph nodes. Oral Oncol. 2002; 38:747-51.

20. Prabhu RS, Hanasoge S, Magliocca KR, Moeller BJ, Milas ZL, Hall WA, El-Deiry M, Wadsworth JT, Higgins KA, Beitler JJ. Extent of pathologic extracapsular extension and outcomes in patients with nonoropharyngeal head and neck cancer treated with initial surgical resection. Cancer. 2014; 120:1499-506.

21. Greenberg JS, Fowler R, Gomez J, Mo V, Roberts D, El Naggar AK, Myers JN. Extent of extracapsular spread: a critical prognosticator in oral tongue cancer. Cancer. 2003; 97:1464-70.

22. Huang DT, Johnson CR, Schmidt-Ullrich R, Grimes M. Postoperative radiotherapy in head and neck carcinoma with extracapsular lymph node extension and/or positive resection margins: a comparative study. Int J Radiat Oncol Biol Phys. 1992; 23:737-42.

23. Michikawa C, Uzawa N, Sato H, Ohyama Y, Okada N, Amagasa T. Epidermal growth factor receptor gene copy number aberration at the primary tumour is significantly associated with extracapsular spread in oral cancer. Br $\mathrm{J}$ Cancer. 2011; 104:850-5.

24. de Juan J, Garcia J, Lopez M, Orus C, Esteller E, Quer M, Leon X. Inclusion of extracapsular spread in the pTNM classification system: a proposal for patients with head and neck carcinoma. JAMA Otolaryngol Head Neck Surg. 2013; 139:483-8.

25. India Project Team of the International Cancer Genome C. Mutational landscape of gingivo-buccal oral squamous cell carcinoma reveals new recurrently-mutated genes and molecular subgroups. Nat Commun. 2013; 4:2873.

26. Koch WM, Brennan JA, Zahurak M, Goodman SN, Westra WH, Schwab D, Yoo GH, Lee DJ, Forastiere AA, Sidransky D. p53 mutation and locoregional treatment failure in head and neck squamous cell carcinoma. J Natl Cancer Inst. 1996; 88:1580-6.
27. Poeta ML, Manola J, Goldwasser MA, Forastiere A, Benoit N, Califano JA, Ridge JA, Goodwin J, Kenady D, Saunders $\mathrm{J}$, et al. TP53 mutations and survival in squamous-cell carcinoma of the head and neck. N Engl J Med. 2007; 357:2552-61.

28. Neskey DM, Osman AA, Ow TJ, Katsonis P, McDonald T, Hicks SC, Hsu TK, Pickering CR, Ward A, Patel A, et al. Evolutionary Action Score of TP53 Identifies HighRisk Mutations Associated with Decreased Survival and Increased Distant Metastases in Head and Neck Cancer. Cancer Res. 2015; 75:1527-36.

29. Muller PA, Vousden KH. Mutant p53 in cancer: new functions and therapeutic opportunities. Cancer Cell. 2014; 25:304-17.

30. Osman AA, Neskey DM, Katsonis P, Patel AA, Ward AM, Hsu TK, Hicks SC, McDonald TO, Ow TJ, Alves MO, et al. Evolutionary Action Score of TP53 Coding Variants Is Predictive of Platinum Response in Head and Neck Cancer Patients. Cancer Res. 2015; 75:1205-15.

31. Murugan AK, Munirajan AK, Tsuchida N. Ras oncogenes in oral cancer: the past 20 years. Oral Oncol. 2012; 48:38392.

32. Chau NG, Li YY, Jo VY, Rabinowits G, Lorch JH, Tishler RB, Margalit DN, Schoenfeld JD, Annino DJ, Goguen LA, et al. Incorporation of Next-Generation Sequencing into Routine Clinical Care to Direct Treatment of Head and Neck Squamous Cell Carcinoma. Clin Cancer Res. 2016.

33. Kang CJ, Lin CY, Yang LY, Ho TY, Lee LY, Fan KH, Wang HM, Huang SF, Chang KP, Fang KH, et al. Positive clinical impact of an additional PET/CT scan before adjuvant radiotherapy or concurrent chemoradiotherapy in patients with advanced oral cavity squamous cell carcinoma. J Nucl Med. 2015; 56:22-30.

34. Laramore GE, Scott CB, al-Sarraf M, Haselow RE, Ervin TJ, Wheeler R, Jacobs JR, Schuller DE, Gahbauer RA, Schwade JG, et al. Adjuvant chemotherapy for resectable squamous cell carcinomas of the head and neck: report on Intergroup Study 0034. Int J Radiat Oncol Biol Phys. 1992; 23:705-13.

35. Rosenthal DI, Harris J, Forastiere AA, Weber RS, Ridge JA, Myers JN, Garden AS, Kuettel MR, Sidhu K, Schultz CJ, et al. Early postoperative paclitaxel followed by concurrent paclitaxel and cisplatin with radiation therapy for patients with resected high-risk head and neck squamous cell carcinoma: report of the phase II trial RTOG 0024. J Clin Oncol. 2009; 27:4727-32.

36. Harari PM, Harris J, Kies MS, Myers JN, Jordan RC, Gillison ML, Foote RL, Machtay M, Rotman M, Khuntia $\mathrm{D}$, et al. Postoperative chemoradiotherapy and cetuximab for high-risk squamous cell carcinoma of the head and neck: Radiation Therapy Oncology Group RTOG-0234. J Clin Oncol. 2014; 32:2486-95.

37. Bourhis J, Overgaard J, Audry H, Ang KK, Saunders M, Bernier J, Horiot JC, Le Maitre A, Pajak TF, Poulsen MG, et al. Hyperfractionated or accelerated radiotherapy in head 
and neck cancer: a meta-analysis. Lancet. 2006; 368:84354.

38. Lee LA, Huang CG, Liao CT, Lee LY, Hsueh C, Chen TC, Lin CY, Fan KH, Wang HM, Huang SF, et al. Human papillomavirus-16 infection in advanced oral cavity cancer patients is related to an increased risk of distant metastases and poor survival. PLoS One. 2012; 7:e40767. 